UDK: 338.23:336.74

DOI: $10.1515 / j c b t p-2015-0008$
* International Institute

of Islamic Economics,

International Islamic

\section{Revival of Legacy of Tooke and Gibson: Implications for Monetary Policy}

E-mail:

atiqurrehman@iiu.edu.pk

\begin{abstract}
The monetary policy rules used by central banks these days are based on the assumption that inflation could be reduced by increasing interest rate. On contrary, Tooke (1774-1858), the forefather of monetary economics, was of the view that the relationship between interest rate and inflation should be positive. His view was based on simple logic, 'interest is a part of cost, and therefore, the increase in interest rate should increase inflation by increasing cost of production (Tooke, 1838)'. Tooke's view has got support from a number of empirical evidence including Gibson (1923) who found positive correlation between two variables for UK data over a period of 200 years. On the other hand, mainstream economic thinking on which the actual monetary practices are based ignored any possibility of positive relationship between interest rate and inflation throughout the history. The existence of Tooke's cost side effects of monetary policy is a serious concern because if these effects exist than the use of monetary policy would be counterproductive. Using the data from entire globe, I attempt to explore the nature of relationship between the interest rate and inflation. I found that the data supports the perception of Tooke and Gibson and denies that the effectiveness of monetary policy currently adapted by the correlation between interest rate and inflation is positive. The results are robust to sample size, sample period, and various definitions of interest rate and inflation.
\end{abstract}

Keywords: Cost Channel, Gibson Paradox, Tooke Banking School Theory

JEL Classification: E40, E42, E52 


\section{Background}

This research started with a surprise, and my exploration into the issue has given rise to even bigger surprises. As an instructor of econometrics, I gave an assignment to my students asking them to explore the relation between interest rate and inflation for different countries. Every student submitting me the assignment came up with either no relationship or a positive relationship between the two variables. This was my first surprise, which was opposite to what I knew about the relationship between these two variables. In my monetary economics course, I have studied that increase in interest rate is used as a tool to reduce inflation. If so, then what is wrong with the students coming up with quite contradictory results?

My further exploration into the issue revealed that Thomas Tooke, the forefather of monetary theory and founder of Tooke Banking School theory, was of the view that the relationship between interest rate and inflation should be positive. His logic was quite simple; 'the interest rate is a part of cost, therefore increase in interest rate would increase the cost of production and would raise the price level'. However, mainstream economists throughout the history had quite contradictory perception regarding the relationship between two variables. Therefore, when Gibson (1923) observed the positive relationship between the two variables, it was taken as a paradox by the economists, and for decades, economists assumed this observation as a theory-less phenomenon.

In late seventies and eighties, economists have come up with an explanation of Gibson paradox which was nothing but a re-iteration of the Tooke's thought. This explanation is usually referred as Cost Channel of Monetary Transmission Mechanism or the Supply Side effects of monetary policy. It says that the rise in interest rate will increase the cost of production for the producers and the producers will reduce the supply at existing price level. This will raise the equilibrium price level; hence the inflation in the economy would tend to rise.

The monetary practices today are based on the assumptions that the relationship between interest rate and inflation is negative; therefore interest rate is increased to reduce inflation. If Tooke's perception is valid, then the policy of increasing interest rate to reduce inflation would be counterproductive and the remedy would increase the disease. Therefore, it is extremely important to explore whether the historical data supports the Tooke's theory or the perception of mainstream economists. This issue has been investigated by numerous researchers in recent decades, however, these studies are limited to one or few countries and the results could be regarded as sample specific observations. In this study I have utilized 
all available data from the entire globe. I have used different sample periods and different time series lengths, with different definitions of interest rates and inflation. I try to summarize these results, but before we go to the results, let us review some theoretical background of the relation between interest rate and prices.

\section{An Overview of Monetary Practices}

In the past, most frequently used tool of monetary policy was the changes in money supply via open market operations. However, nowadays, interest rate has taken place of the major tool of monetary policy. But with respect to their effects, the monetary policy actions could be divided into two categories:

Tight Monetary Policy: the tight monetary policy refers to an increase in interest rate or a reduction in money supply. The two actions are equal with respect to their final impact because any of these two actions would lead to the other. If interest rate is increased, people will prefer to keep money into profit earning accounts to earn profit, and the more liquid types of the money will reduce in size. On the other hand, if money supply is reduced, the banks would increase the interest rate. A tight monetary policy is used when the inflation is high, with the expectation that this would lead to reduction in inflation.

Loose Monetary Policy: this refers to either decrease in interest rate or increase in money supply by the central bank. By the similar logic, the loose monetary policy is assumed to have the same effect, whether interest rate or money supply is used as policy variable. Loose monetary policy is used to increase the economic activity, but it is assumed that aggregate price level will increase by using the loose monetary policy.

\section{How Monetary Policy Affects the Prices?}

There are multiple causal paths connecting a monetary policy action to the price level. These paths are usually called Monetary Transmission Channels. Literature lists a lot of channels including the interest rate channel, bank lending channel, exchange rate channel etc. The details of these transmission channels could be found in Ghaffari (2013). However, ultimate impact of the monetary policy action is either through change in aggregate demand or through change in aggregate supply. Thus the channels could be classified as the supply side channel or the demand side channel. Ghaffari (2013) beautifully explains this classification of the monetary transmission channels into demand and supply side channels. 
Consider the use of tight monetary policy by a central bank by decrease in money supply and/or increase in interest rate. By an increment in the interest rate, the consumer will prefer to keep the money in interest earning deposits and more liquid forms of money in possession will decrease. Consumption, especially on the durable items, will decrease, leading to a reduction in aggregate demand in the economy. This reduction in aggregate demand will result in a downward pressure on the equilibrium price level and output. There are a number of other causal paths having similar effects on the aggregate demand that can also be categorized as demand side channels of monetary transmission.

On the other hand, consider the tight monetary policy used by central bank. The increase in policy rate affects all kinds of interest rates and the cost of borrowing for investors and firms increases. Thus the cost of production will increase, shifting the aggregate supply curve to the left. This will put upward pressure on equilibrium price level. Some other transmission channels have similar impacts on the aggregate supply and can be categorized as supply side channels of monetary transmission.

In fact without paying much attention to the exact transmission channel, one can analyse the effect of these channels on the price level using their classification into supply and demand side channels. The effects of demand and supply side transmission channels are presented in Rehman (2014) and Ghaffari et. al. (2014) which is summarized as under:

\subsection{The Demand Side Effect of Tight Monetary Policy:}

Suppose the monetary actions of central banks effect the economy only through the demand side channels as perceived by monetary authorities. The effects of tight monetary policy in this case are summarized in Figure 1.

The left panel is state of equilibrium in an economy before monetary intervention. The equilibrium output is $\mathrm{Y} 1$ and price is $\mathrm{P} 1$. The monetary shock shifts the $\mathrm{AD}$ curve inward as a result the price and output both decrease to P2 and Y2 respectively. As seen in the figure, the new equilibrium output is smaller than the previous equilibrium output and the price level is lower than the previous equilibrium. Thus if the monetary action is affecting the economy through demand channel only, the final effect would be a reduction in both output and inflation. In this case, the tight monetary policy could be used to reduce inflation; however, the output will decrease by this action. The central bank's actions are based on the assumption that monetary policy actions affect the economy through this type of transmission channels. 
Figure 1: Effect of tight monetary policy through demand side channels
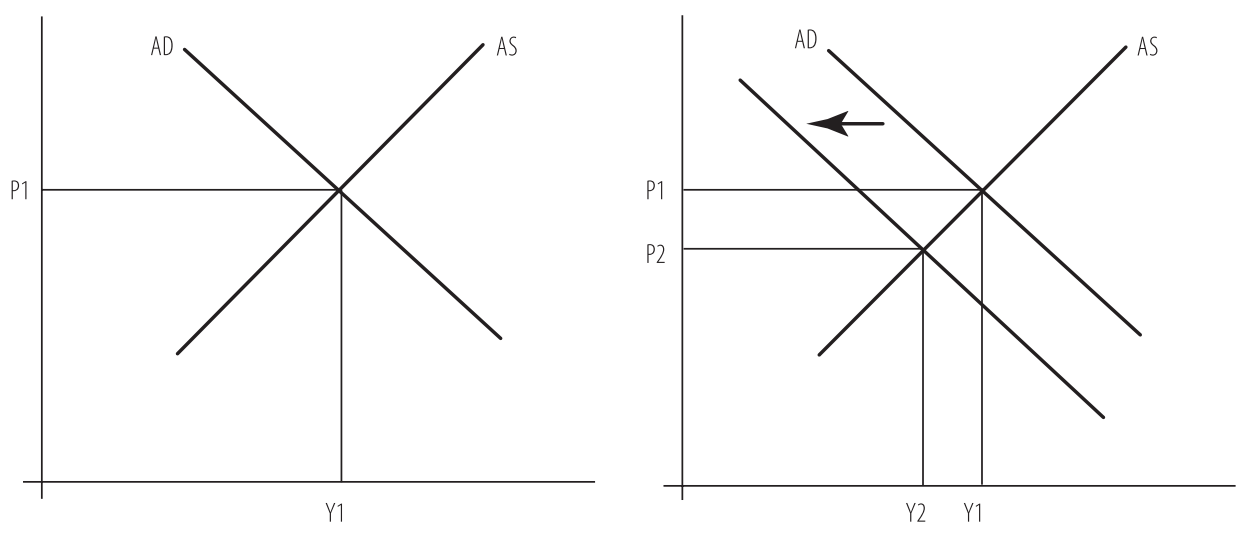

\subsection{The Cost Side Effects of Tight Monetary Policy}

Suppose the monetary actions of central banks affect the economy only through the cost/supply side channels as perceived by Tooke. The effects of tight monetary policy in this case are summarized in Figure 2.

Figure 2: Effect of tight monetary policy through supply side channels
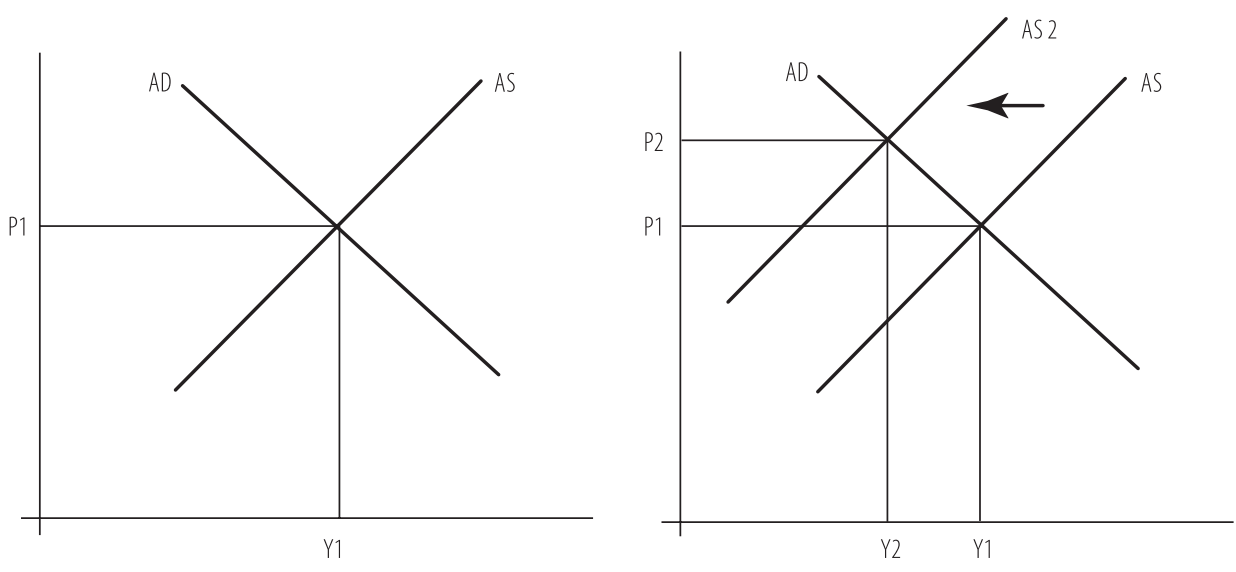

Figure 2 shows the effect of rise in interest rate via the supply side or cost side channels. The left panel is state of equilibrium before interest based intervention. The equilibrium output and price are Y1 and P1, respectively. The monetary 
shock shifts AS curve to the left and, as a result, output decreases to Y2 and price increases to $\mathrm{P} 2$, respectively. One can see that the new equilibrium price is higher than the previous. Thus a tight monetary policy which is assumed to reduce inflation would be counterproductive if the monetary actions are affecting economy through the cost/supply side. However, the new equilibrium output is again less than the previous output indicating that the action would negatively affect the output growth.

\subsection{The Interaction of Cost and Demand Side Effects}

Consider a more realistic case that monetary policy actions are affecting the economy simultaneously through the demand and cost sides. The effects on inflation and output in this case are summarized in Figure 3.

The monetary shock simultaneously shifts AS curve and aggregate demand curve. New equilibrium occurs at (P1, Y2) which shows the price remains the same (at P1) and only output decreases (Y1 to Y2) and equilibrium occurs at P1 price and Y2 output.

Thus, if both demand and supply side channels are working, a tight monetary policy would result in a twofold reduction in output with no effect on price level. Obviously, it would be undesirable to use a monetary tool which is doing nothing to the price level but reducing the output.

Figure 3: Effect of tight monetary policy through supply and demand channels simultaneously
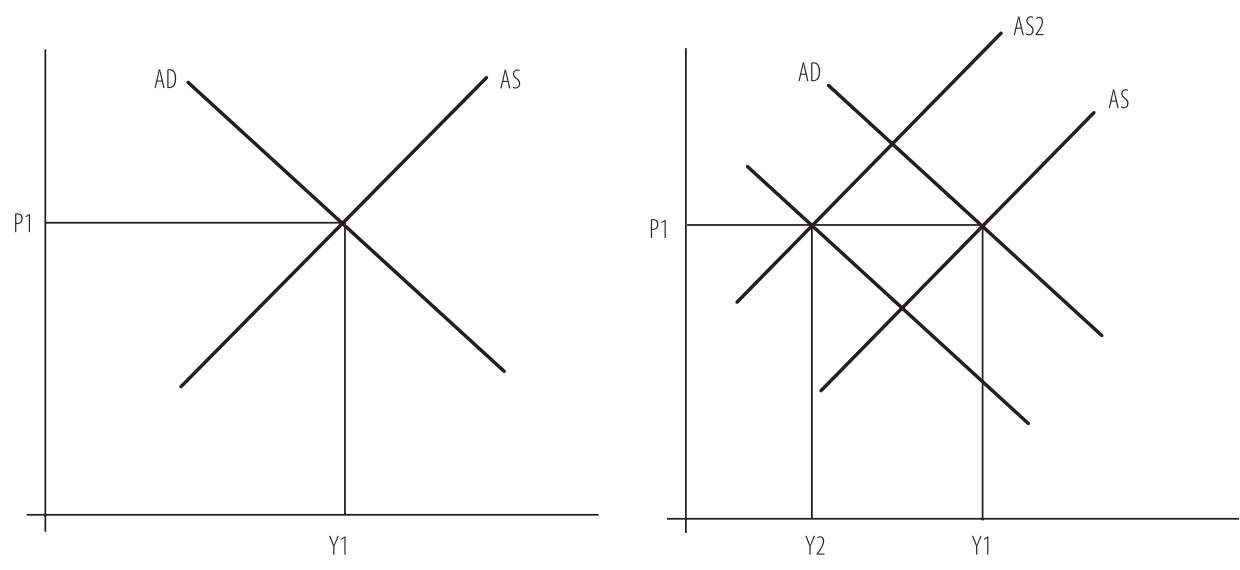
The three cases presented above make it clear that the use of tight monetary policy to reduce inflation could be justified only if monetary actions affect the economy only through demand side channels. If the cost side channels are dominant, the remedy would worsen the disease, and if economy is affected simultaneously by both the demand and supply side channels, this would have a very bad effect on aggregate output.

\section{Does the Monetary Policy Work?}

Most of central banks today use short term interest rate as a tool of monetary policy. Central banks assume that by increasing the interest rate, the demand channel of monetary transmission mechanism will work and inflation should decrease. In this policy formulation, they ignore the counterproductive channel of transmission through cost side channels and they also ignore the possibility of cancellation effect, the interaction of cost and demand side.

On the other hand, there is a long history of evidence against the working of the demand channel of monetary transmission mechanism. The positive relation between interest rate and inflation was predicted on theoretical grounds by Tooke (1838) and the empirical evidence of this was provided by Gibson (1923). Gibson found positive correlation between interest rates and prices in the UK data over a period of 200 years. This finding was against the perception of mainstream economic thought so they named it the Gibson Paradox. In the same period, Kitchin (1923) and Peake (1928) also report evidence of a positive correlation between short-term interest rates and prices. Keynes, one of the most influential economists of the twentieth century, has considered the evidence presented by Gibson as 'one of the most completely established empirical facts within the whole field of quantitative economics (Keynes, 1936)'. However, despite all this, monetary policy has always been based on the assumption of the demand channel of monetary transmission mechanism without paying any attention to the possibility of existence of supply side effects of the monetary policy actions.

Wright Patman, the Chairman of the Joint Economic Committee of US Congress, presented his analysis of monetary policy in the following words, 'raising interest rates to fight inflation is like throwing gasoline on fire' (United States, Congress. Joint Economic Committee, 1977), however, this strong statement of Patman could not change monetary policy actions and many central banks are using the same gasoline to fight the fire of inflation. 
In recent years, many studies have explored the possibility of existence of cost side effects of monetary transmissions e.g. Barth \& Ramey (2001) used data from 1960-96 and found the evidence of positive correlation of interest rate and prices. Following this research, many papers started exploring cost channel. In the following few years, Chowdhury et al (2006), Ravenna and Walsh (2006), and Tillmann (2008) found that the nominal interest rate has a significant positive effect on inflation in the US economy. In another study Tillmann (2008) found a positive relationship between interest rate and inflation in the UK and the euro area. Qiang and Xin (2010) found significant presence of cost channel of MTM in the Chinese economy and they further conclude that the cost channel not only weakened the capacity of monetary policy to reduce inflation but also reduced GDP to a large extent. Ali (2012) analyses the high interest rate policy (Taylor rule) to control inflation and its supply side effects and concluded that higher interest rate is not an effective tool in the presence of supply side effects of interest rate and increases in the nominal interest rate is unwise policy to cope with inflation. Passamani and Tamborini (2006) found the presence of the credit cost channel of monetary transmission mechanism in Italy and Germany. They conclude that in both countries' firms heavily reliance on bank loan (credit channel) make aggregate supply sensitive to bank interest rates (cost channel) which are affected by the central bank's interbank rate.

All of these studies challenge the use of tight monetary policy as a tool to control inflation and assert that monetary authorities must take into account the cost side effects while analysing the effects of monetary actions. However, on the practice side, most of central banks today are using the Taylor Rule for deciding on monetary actions, which is based on the assumption of demand side effects of the monetary transmission without paying any attention to the cost side effects.

\section{Contribution of this Study}

This study evaluates the relationship between interest rate and inflation for (i) all countries around the globe, (ii) for various definitions of interest rate and various definitions of inflation, (iii) for a variety of time periods and time series lengths, and (iv) for different lag intervals between monetary action and inflation. Thus a fairly robust summary of the relationship between two variables is presented which clarifies the direction of relationship between two variables and evaluates the validity of contemporary monetary policy. 


\section{Data and Methodology}

\subsection{Data}

Data on interest rate and inflation from the entire globe is used in this study. The data used in this study are obtained from the International Financial Statistics. All available data on the prices and interest were utilized for the current study. The IFS provides data on seven measures of interest rate which are as follows:

1. Central Bank Policy Rate (CBPR)

2. Deposit Rate (DEPR)

3. Discount Rate (DR)

4. Government Bond Yield (GBY)

5. Lending Rate (LR)

6. Money Market Rate (MMR)

7. Treasury Bill Rate (TBR)

Similarly, data on two measure of inflation are available which are as follows:

1. Consumer Price Inflation (CPI)

2. GDP Deflator Inflation (GDPDEF)

The seven measures of interest rate and two measures of inflation formulate 14 combinations of measures of interest rate and inflation. The relationship between interest rate and inflation was calculated for all these combinations, subject to availability of the respective series.

\subsection{Sample Period}

For the fourteen combinations mentioned in the section 6.1, I have collected data for the following sample specifications.

Time Series length $=15$ years i.e. 60 observations, for time period 1966-1980, 1976-1990, 1986-2000, 1996-2010.

Time Series length $=20$ years i.e. 80 observations, for time period 1965-1984, 1975-1994, 1985-2004, 1993-2012.

Time Series length $=30$ years i.e. 120 observations, for time period 1965-1994, 1975-2004, and 1983-2012 


\subsection{Procedures}

The present study aims to replicate the procedures of Gibson (1923) on the data from the entire world. Therefore, this analysis looks only at the direction of relationship between two variables, without going into details of exact transmission channels through the correlation coefficients. Though the correlations without a structural model provide only a clue instead of proof of the relationship under consideration, however, the similar clues from a large number of samples can formulate very strong evidence. Therefore the results are capable of giving a clear picture of the direction of relationship between two variables and present a fairly clear picture of the impact of monetary policy on the target variable.

Following tools were used to analyse the relationship between two variables.

1. Pearson Bivariate Correlation

2. Cross-Serial Pearson Correlation

The Pearson correlation is just standardized first order co-variance of interest and inflation calculated using the following formula:

$$
\operatorname{Corr}\left(\pi_{\tau}, i_{\tau}\right)=\frac{\operatorname{Cov}\left(\pi_{\tau}, i_{\tau}\right)}{\sqrt{\operatorname{SD}\left(\pi_{\tau}\right) S D\left(i_{\tau}\right)}}
$$

The Cross-Serial Pearson Correlation is the correlation between inflation and lag value of interest rate.

$$
\operatorname{Corr}\left(\pi_{\tau}, i_{\tau-j}\right)=\frac{\operatorname{Cov}\left(\pi_{\tau}, i_{\tau-j}\right)}{\sqrt{S D\left(\pi_{\tau}\right) S D\left(i_{\tau-j}\right)}}
$$

Since cross-serial correlation involves a lag of interest rate and the current value of inflation, it can measure the effect past changes in interest rate interventions on forthcoming inflation.

\section{Results}

Fourteen pairs of different measures interest rate and inflation were calculated for this study. For some pairs, I was able to get data for a large number of countries, but for some pairs, the data were available only for few countries. All of these pairs collectively formulate thousands of results. It is really tough job to summarize the results of a large computation in a small volume; however, I have tried to summarize these results so that overall of overall relationship between inflation and interest rate could be uncovered. 
For the fourteen pairs of definitions of interest rate and inflation, I was able to collect 2,636 data sets. I have calculated contemporaneous correlation and crossserial correlation for lags 1-4 for each data set. Therefore, a total of 13,180 coefficients were calculated. Of these 13,180 coefficients, only $19 \%$ of the correlation coefficients were having negative sign. These include the coefficients whose distance from zero is not statistically significant.

Figure 4 summarizes the distribution of computed contemporaneous correlation coefficients for different sample periods where the sample size was 60 observations (15 years quarterly data). The histograms of the contemporaneous correlation for 15-year time series are given in Figure 4 for different time periods. These histograms summarize the results for all fourteen pairs of interest rate and inflation, for the countries from entire globe.

The figure shows that the histograms are centred on the positive side of real line, indicating that the evidence for positive relation between interest rate and inflation are stronger. Of 1,187 results summarized in these histograms, only $18 \%$ were carrying a negative sign. For sample size 60, the correlation coefficient becomes statistically signifi-

Figure 4: Correlation between inflation and interest rate, time series length = 15 years, 60 observations

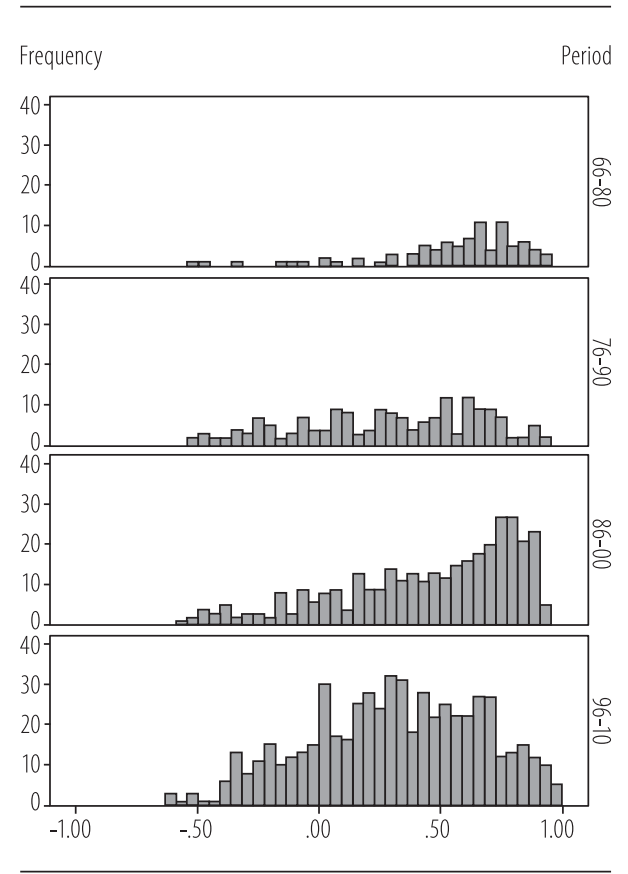
cant if its absolute value is larger than 0.25 . From the results summarized above, $64 \%$ of the correlation coefficients were significant with positive sign and $29 \%$ were statistically insignificant. Only $7 \%$ coefficients were significant with a negative sign. We can see that a lot of data lies right of 0.5 , indicating very high correlation between interest rate and inflation.

These results imply that the major portion of correlations fall in two categories: (i) insignificant, the coefficients close to zero on both positive and negative side of real line (ii) positive, the coefficients on positive side of real line which are away from zero. The number of significant correlation with negative signs is very small, indicating a failure of monetary policy actions. 
Figure 5: Correlation between inflation and interest rate, time series length = 30 years, 120 observations

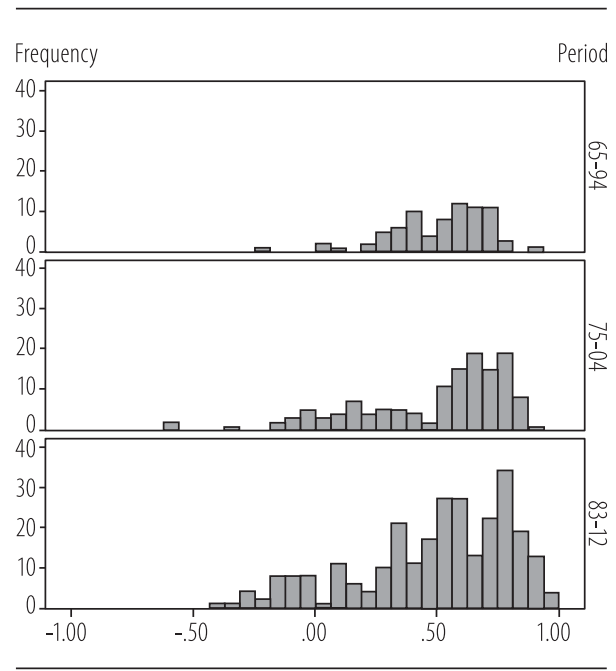

Figure 6: Correlation between inflation and lagged interest rate, time series length $=15$ years, 60 observations

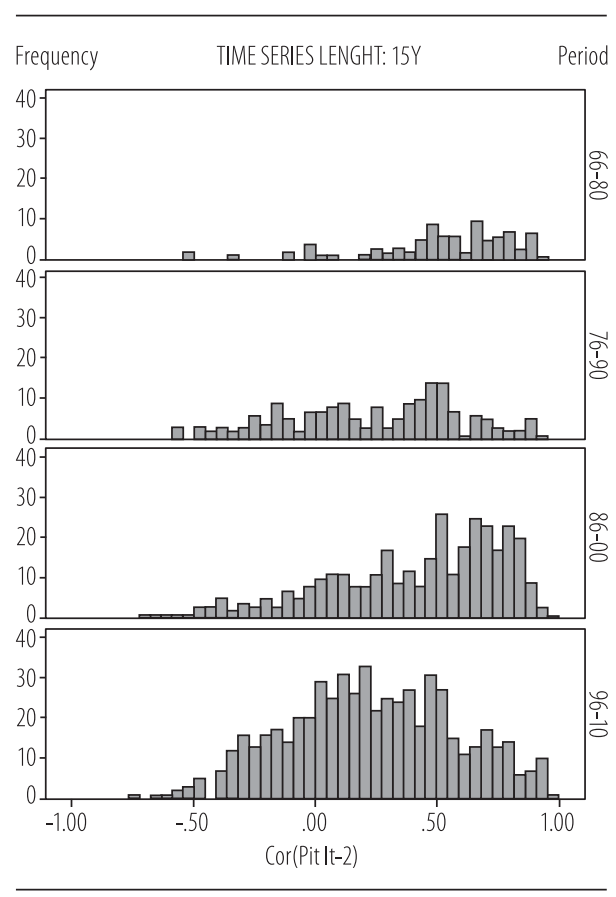

Figure 5 gives the histogram of contempraneous correlation for thirty years data. The histograms are not very different from the histogram of 15 years data series. The centers of the histograms are again lying on the positive side of real line and the proportion of data on the negative side of real line is very small. For 30 years data, $84 \%$ coefficients were carrying a positive sign and 70 coefficients were positive and statistically significant. Only $2 \%$ coefficients had a negative and significant coefficients. This implies that the evidence of positive correlation between inflation and interest become stronger when the time series length increases.

However, it is possible that the positive correlation is observed because of ignoring the lag factor. Monetary policy announced by central banks should not immediately change the target variable. Instead, it affects the target variable i.e. inflation via a causal channel involving multiple variables. If this is true, then a change in interest rate should affect inflation after some time lag. If the monetary policy works as described in the textbooks and as perceived by mainstream monetary economists, then a tight monetary policy should be followed by a reduction in inflation and cross-serial correlation between inflation and lagged interest rate should be negative. Figure 6 gives the histograms of cross-serial correlation coefficients between inflation and second lag of interest rate. The results are quite similar to the results ob- 
served in case of contemporaneous correlation. The histograms again have centre on the positive side of real line, and the percentage of correlations having negative signs is very small. In $35 \%$ cases, the correlation is not significant, and in 57\% cases, correlation is significant with a positive sign. Only $8 \%$ of the correlation coefficients carry a negative and significant sign.

The analysis of correlation coefficients for the $1^{\text {st }}, 3^{\text {rd }}$ and $4^{\text {th }}$ order cross-serial correlation also yields similar results. The details of these results I skip for the sake of parsimony.

However, the results summarized in Figures 4- 6 do not distinguish between various definitions of interest rate/inflation. In order to see how definitions of interest rate/inflation change the results, the distribution of correlation coefficients for 15 years data is summarized in Table 1 separately for 14 pairs of interest rate and inflation.

Column 1 of Table 1 gives the number of countries for which the pair of interest rate and inflation was available. Column 2-4 give the three quartiles for contemporaneous correlation coefficients, column 5-7 and 8-10 summarize the distribution for $2^{\text {nd }}$ order and fourth order cross serial correlation respectively.

The first row of Table 1 summarizes the information on correlation between CPI inflation and the Central Bank Policy Rate for period 1976-1990. The data on these two variables for this period are available for nine countries of the world. Therefore, we have nine coefficients of contemporaneous correlation and nine coefficients for each of lags from lags 1 to 4 . The nine coefficients of contemporaneous correlation have a positive median of indicating a dominance of positive relation between two variables. The medians of lagged correlation are also positive, strengthening the evidences of positive relation between two variables. The pair 'CPI inflation, deposit interest rate' is available for 21 countries of the world and the distribution of correlation coefficient is again positively centred. The correlation between CPI inflation and all other kinds of interest rates have medians on positive side of real line. In many cases, the medians are greater than 0.25 , indicating that more than 50 percent of correlation coefficients are positive and significant. In a large number of cases, the first quartile is also positive, indicating that more than $75 \%$ of the calculated correlation coefficients carry a positive sign. For the time period 1996-2010, data is available for a larger number of countries. We have the pair 'CPI inflation, CBPR' available for 24 countries and the pair 'CPI inflation, Deposit Rate' is available for 102 countries of the world. For this time period, we observed that in the majority of cases, the 1st quartile of computed correlation is also positive, indicating that more than $75 \%$ of correlation coef- 
ficients are positive. For the period 1996-2010, the first quartile of contemporaneous for all the pairs is positive, except the pairs containing Government Bond Yield, but the absolute value is smaller than 0.25 , indicating that the correlation is insignificant. If we consider the second order lagged correlation, we see that there are more negative signs for the first quartiles, none of these first quartiles is smaller than 0.25 . This indicates that for more than $75 \%$ cases, the correlation is either positive or insignificant. Same picture emerges if we analyse the fourth order correlation. The results from the first and third order correlations which are not summarized in this table also provided same results. We also see that no significant difference appears in the distributional characteristics of correlation by changing the definition of interest rate and/or inflation. This indicates that the evidence of positive relationship between interest rate and inflation are robust to the kind of interest rate and do not change with any change in the definition of interest rate. 
Table 1: Summary Statistics for Correlation Between Interest Rate and Inflation, Time Series Length 15 Years, 60 Quarters

\begin{tabular}{|c|c|c|c|c|c|c|c|c|c|c|c|c|}
\hline \multirow{2}{*}{$\begin{array}{c}\text { Quarters } \\
\text { Period }\end{array}$} & \multirow{2}{*}{$\begin{array}{l}\text { Inflation } \\
\text { Type }\end{array}$} & \multirow{2}{*}{$\begin{array}{c}\text { Interest } \\
\text { Type }\end{array}$} & \multirow{2}{*}{ Countries } & \multicolumn{3}{|c|}{$\operatorname{corr}\left(\pi_{\tau}, i_{\tau}\right)$} & \multicolumn{3}{|c|}{$\operatorname{corr}\left(\pi_{\tau}, i_{\tau-2}\right)$} & \multicolumn{3}{|c|}{$\operatorname{corr}\left(\pi_{\tau}, i_{\tau-4}\right)$} \\
\hline & & & & Q1 & Q2 & Q3 & Q1 & Q2 & Q3 & Q1 & Q2 & Q3 \\
\hline \multirow{14}{*}{$76-90$} & \multirow{7}{*}{ CPI } & CBPR & 9 & -.21 & .30 & .45 & -.16 & .23 & .44 & -.19 & .24 & .34 \\
\hline & & DEPR & 21 & -.06 & .17 & .63 & -.11 & .12 & .45 & -.18 & -.04 & .43 \\
\hline & & DR & 19 & -.30 & .32 & .69 & -.18 & .27 & .58 & -.28 & .15 & .43 \\
\hline & & GBY & 21 & .26 & .53 & .74 & .09 & .49 & .69 & -.12 & .26 & .55 \\
\hline & & LR & 16 & .12 & .24 & .58 & .02 & .23 & .41 & -.19 & .04 & .37 \\
\hline & & MMR & 22 & .05 & .27 & .57 & -.01 & .30 & .50 & -.13 & .23 & .37 \\
\hline & & TBR & 18 & -.10 & .16 & .63 & -.16 & .09 & .51 & -.25 & -.12 & .38 \\
\hline & \multirow{7}{*}{ GDPDEF } & CBPR & 5 & -.36 & -.11 & .26 & -.37 & .00 & .14 & -.36 & -.15 & .12 \\
\hline & & DEPR & 6 & .04 & .58 & .64 & .07 & .48 & .56 & -.11 & .27 & .47 \\
\hline & & DR & 3 & .51 & .71 & .91 & .47 & .56 & .89 & .28 & .37 & .81 \\
\hline & & GBY & 12 & .18 & .38 & .53 & .12 & .29 & .53 & -.13 & .23 & .43 \\
\hline & & LR & 5 & .35 & .44 & .60 & .37 & .39 & .43 & .21 & .22 & .25 \\
\hline & & MMR & 12 & -.07 & .15 & .45 & -.05 & .22 & .41 & -.15 & .16 & .29 \\
\hline & & TBR & 7 & -.08 & .44 & .49 & .05 & .37 & .46 & .16 & .26 & .38 \\
\hline \multirow{14}{*}{$96-10$} & \multirow{7}{*}{ CPI } & CBPR & 24 & .25 & .43 & .65 & .11 & .37 & .59 & -.11 & .11 & .31 \\
\hline & & DEPR & 102 & .04 & .36 & .63 & -.01 & .28 & .50 & -.14 & .05 & .36 \\
\hline & & DR & 56 & .02 & .30 & .58 & -.07 & .18 & .48 & -.14 & .09 & .31 \\
\hline & & GBY & 29 & -.06 & .14 & .23 & -.14 & .11 & .26 & -.17 & -.01 & .12 \\
\hline & & LR & 96 & .01 & .32 & .61 & -.08 & .21 & .49 & -.16 & .10 & .34 \\
\hline & & MMR & 60 & .21 & .42 & .63 & .08 & .35 & .63 & -.10 & .15 & .38 \\
\hline & & TBR & 50 & .00 & .27 & .51 & -.04 & .17 & .44 & -.20 & .04 & .25 \\
\hline & \multirow{7}{*}{ GDPDEF } & CBPR & 11 & .10 & .30 & .68 & -.03 & .17 & .53 & -.16 & -.08 & .42 \\
\hline & & DEPR & 29 & .20 & .40 & .58 & .09 & .22 & .49 & -.12 & .11 & .26 \\
\hline & & DR & 16 & .17 & .33 & .61 & .20 & .25 & .53 & -.02 & .14 & .45 \\
\hline & & GBY & 23 & -.16 & .02 & .15 & -.15 & .04 & .14 & -.25 & -.10 & .08 \\
\hline & & LR & 26 & .20 & .38 & .54 & .00 & .23 & .47 & -.13 & .07 & .47 \\
\hline & & MMR & 32 & .19 & .34 & .58 & .11 & .27 & .56 & -.07 & .06 & .47 \\
\hline & & TBR & 19 & .15 & .28 & .65 & -.02 & .23 & .56 & -.06 & .08 & .44 \\
\hline
\end{tabular}


Table 2: Summary Statistics for Correlation Between Interest Rate and Inflation, Time Series Length 30 Years, 120 Quarters

\begin{tabular}{|c|c|c|c|c|c|c|c|c|c|c|c|c|}
\hline \multirow{2}{*}{ Period } & \multirow{2}{*}{$\begin{array}{c}\text { Inflation } \\
\text { Type }\end{array}$} & \multirow{2}{*}{$\begin{array}{l}\text { Interest } \\
\text { Type }\end{array}$} & \multirow{2}{*}{ Countries } & \multicolumn{3}{|c|}{$\operatorname{corr}\left(\pi_{\tau}, i_{\tau}\right)$} & \multicolumn{3}{|c|}{$\operatorname{corr}\left(\pi_{\tau}, i_{\tau-2}\right)$} & \multicolumn{3}{|c|}{$\operatorname{corr}\left(\pi_{\tau}, i_{\tau-4}\right)$} \\
\hline & & & & Q 1 & Q 2 & Q3 & Q 1 & Q 2 & Q 3 & Q 1 & Q 2 & Q 3 \\
\hline \multirow{14}{*}{$65-94$} & \multirow{7}{*}{$\mathrm{CPI}$} & CBPR & 5 & .09 & .51 & .53 & .06 & .41 & .45 & -.05 & .24 & .29 \\
\hline & & DEPR & 3 & .50 & .70 & .70 & .41 & .59 & .60 & .23 & .40 & .42 \\
\hline & & DR & 10 & .35 & .67 & .73 & .47 & .65 & .69 & .43 & .46 & .59 \\
\hline & & GBY & 15 & .44 & .53 & .67 & .36 & .43 & .56 & .25 & .32 & .46 \\
\hline & & $\mathrm{LR}$ & 4 & .65 & .66 & .70 & .54 & .58 & .63 & .35 & .42 & .54 \\
\hline & & MMR & 7 & .28 & .61 & .69 & .18 & .55 & .62 & .05 & .37 & .41 \\
\hline & & TBR & 7 & .30 & .59 & .61 & .23 & .50 & .57 & .04 & .36 & .45 \\
\hline & \multirow{7}{*}{ GDPDEF } & CBPR & 2 & .34 & .39 & .45 & .38 & .41 & .45 & .37 & .39 & .41 \\
\hline & & DEPR & 3 & .26 & .60 & .61 & .26 & .49 & .57 & .17 & .33 & .44 \\
\hline & & DR & 3 & .41 & .64 & .69 & .44 & .57 & .58 & .35 & .41 & .46 \\
\hline & & GBY & 6 & .30 & .47 & .53 & .19 & .40 & .55 & .06 & .25 & .55 \\
\hline & & $\mathrm{LR}$ & 4 & .42 & .50 & 60 & .37 & .47 & .48 & .21 & .31 & .39 \\
\hline & & MMR & 4 & .45 & .56 & .64 & .45 & .49 & .53 & .29 & .40 & .45 \\
\hline & & TBR & 4 & .35 & .39 & .50 & .30 & .41 & .47 & .18 & .36 & .42 \\
\hline \multirow{14}{*}{$83-12$} & \multirow{7}{*}{ CPI } & CBPR & 10 & .44 & .54 & .72 & .38 & .57 & .74 & .34 & .49 & .67 \\
\hline & & DEPR & 49 & .14 & .38 & 68 & .18 & .33 & .56 & .06 & .29 & .49 \\
\hline & & DR & 28 & .24 & .40 & .58 & .21 & .34 & .63 & .12 & .23 & .57 \\
\hline & & GBY & 21 & .51 & .73 & .80 & .49 & .69 & .79 & .41 & .63 & .73 \\
\hline & & $\mathrm{LR}$ & 37 & .00 & .36 & .56 & -.05 & .25 & .56 & -.05 & .18 & .42 \\
\hline & & MMR & 26 & .37 & .58 & .79 & .22 & .57 & .72 & .13 & .37 & .66 \\
\hline & & TBR & 26 & .10 & .55 & .71 & .06 & .47 & .70 & .05 & .36 & .66 \\
\hline & \multirow{7}{*}{ GDPDEF } & CBPR & 7 & .41 & .53 & .75 & .32 & .53 & .72 & .24 & .46 & .62 \\
\hline & & DEPR & 9 & .57 & .57 & .79 & .49 & .53 & .74 & .37 & .47 & .65 \\
\hline & & DR & 6 & .35 & .62 & .80 & .55 & .73 & .80 & .49 & .58 & .67 \\
\hline & & GBY & 19 & .54 & .66 & .75 & .49 & .62 & .74 & .40 & .58 & .71 \\
\hline & & $L R$ & 10 & .48 & .62 & .75 & .47 & .50 & .72 & .33 & .44 & .62 \\
\hline & & MMR & 14 & .60 & .73 & .80 & .56 & .63 & .77 & .48 & .56 & .75 \\
\hline & & TBR & 10 & .51 & .71 & .77 & .53 & .68 & .76 & .49 & .62 & .71 \\
\hline
\end{tabular}


Table 2 presents the distributional characteristics of correlation for longer time series i.e. 30 years data. The calculations for longer data series reveal that the first quartile is positive for all 14 combinations of interest rate and inflation. This implies that more than $75 \%$ of correlation coefficients are positive for every definition of interest rate and inflation. It can also be observed that in many cases, the first quartile is larger than 0.18 indicating that in more than $75 \%$ of cases, the correlation coefficient is not only positive, but also statistically significant. A change in the definition of interest rate and/or inflation does not change the pattern of results.

Table 3 provides an overview of the percentage of significant correlation coefficients for different time series length and for fourteen pairs of interest rate and inflation. The row 1 of the results summarized in Table 3 depicts that 50 data sets could be obtained for the pair 'CPI inflation and Central Bank Policy Rate' with time series length 15 years. Among the contemporaneous correlation coefficients, $6 \%$ coefficients were significant with a negative sign, and $72 \%$ coefficients were significant with a positive sign. This implies that $22 \%$ of these coefficients were statistically insignificant. If we consider the correlation between inflation and fourth lag of interest rate, the correlative was positive for $46 \%$ of times and negative for $8 \%$ of times. This means that fourth order cross serial correlation was insignificant for about 52\% of the coefficients. For the same pair with time series length of 20 years, 43 correlation coefficients data sets could be obtained. Out of these 43 coefficients, 12\% were significant with negative sign and $70 \%$ were significant with a positive sign. This implies that about $18 \%$ of the correlation coefficients were statistically insignificant. Some 23 data sets for this pair could be obtained with time series length 30 years; $4 \%$ of the correlation coefficients for these data sets carry negative sign and $70 \%$ carry a positive sign. This implies that $26 \%$ of the correlation coefficients were statistically insignificant. We can see from Table 3 that percentage of positive coefficients is at least 4 times that of negative coefficients for all kinds of interest rate, inflation and lag specifications. From the entire results for all types of calculations, $64 \%$ coefficients were positive, and $7 \%$ and $29 \%$ were statistically insignificant. 
Table 3: Summary of significant coefficients with their signs for various kinds of inflation and interest rate

\begin{tabular}{|c|c|c|c|c|c|c|c|c|c|c|c|}
\hline \multirow{2}{*}{ Inflation } & \multirow{2}{*}{ Interest } & \multirow{2}{*}{ Sign } & \multicolumn{3}{|c|}{15 -year time series } & \multicolumn{3}{|c|}{ 20-year time series } & \multicolumn{3}{|c|}{ 30-year time series } \\
\hline & & & Count & $\operatorname{corr}\left(\pi_{\tau}, i_{\tau}\right)$ & $\operatorname{corr}\left(\pi_{\tau}, i_{\tau-4}\right)$ & Count & $\operatorname{corr}\left(\pi_{\tau}, i_{\tau}\right)$ & $\operatorname{corr}\left(\pi_{\tau}, i_{\tau-4}\right)$ & Count & $\operatorname{corr}\left(\pi_{\tau}, i_{\tau}\right)$ & $\operatorname{corr}\left(\pi_{\tau}, i_{\tau-4}\right)$ \\
\hline \multirow{14}{*}{$\mathrm{CPI}$} & \multirow{2}{*}{ CBPR } & Negative & 50 & $6 \%$ & $8 \%$ & 43 & $12 \%$ & $12 \%$ & 23 & $4 \%$ & $4 \%$ \\
\hline & & Positive & & $72 \%$ & $46 \%$ & & $70 \%$ & $53 \%$ & & $70 \%$ & $65 \%$ \\
\hline & \multirow{2}{*}{$\begin{array}{l}\text { DEPR } \\
\text { DE }\end{array}$} & Negative & 192 & $8 \%$ & $12 \%$ & 152 & $7 \%$ & $14 \%$ & 65 & $2 \%$ & $8 \%$ \\
\hline & & Positive & & $59 \%$ & $41 \%$ & & $70 \%$ & $54 \%$ & & $71 \%$ & $62 \%$ \\
\hline & \multirow{2}{*}{ DR } & Negative & 127 & $13 \%$ & $18 \%$ & 104 & $6 \%$ & $9 \%$ & 54 & $4 \%$ & $4 \%$ \\
\hline & & Positive & & $59 \%$ & $41 \%$ & & $73 \%$ & $60 \%$ & & $78 \%$ & $63 \%$ \\
\hline & \multirow{2}{*}{ GBY } & Negative & 92 & $1 \%$ & $8 \%$ & 86 & $2 \%$ & $5 \%$ & 54 & $0 \%$ & $0 \%$ \\
\hline & & Positive & & $65 \%$ & $53 \%$ & & $80 \%$ & $66 \%$ & & $100 \%$ & $94 \%$ \\
\hline & \multirow{2}{*}{ LR } & Negative & 176 & $9 \%$ & $15 \%$ & 131 & $10 \%$ & $17 \%$ & 51 & $10 \%$ & $12 \%$ \\
\hline & & Positive & & $59 \%$ & $34 \%$ & & $66 \%$ & $45 \%$ & & $73 \%$ & $55 \%$ \\
\hline & \multirow{2}{*}{ MMR } & Negative & 121 & $7 \%$ & $8 \%$ & 95 & $6 \%$ & $9 \%$ & 45 & $2 \%$ & $4 \%$ \\
\hline & & Positive & & $69 \%$ & $43 \%$ & & $75 \%$ & $56 \%$ & & $87 \%$ & $71 \%$ \\
\hline & \multirow{2}{*}{$\begin{array}{l}\text { TBR } \\
\text { T }\end{array}$} & Negative & 109 & $8 \%$ & $15 \%$ & 95 & $5 \%$ & $12 \%$ & 47 & $6 \%$ & $11 \%$ \\
\hline & & Positive & & $58 \%$ & $39 \%$ & & $67 \%$ & $49 \%$ & & $74 \%$ & $62 \%$ \\
\hline \multirow{14}{*}{ GDPDEF } & \multirow{2}{*}{ CBPR } & Negative & 25 & $12 \%$ & $20 \%$ & 23 & $4 \%$ & $4 \%$ & 14 & $0 \%$ & $0 \%$ \\
\hline & & Positive & & $64 \%$ & $40 \%$ & & $65 \%$ & $39 \%$ & & $79 \%$ & $71 \%$ \\
\hline & \multirow{2}{*}{ DEPR } & Negative & 50 & $2 \%$ & $6 \%$ & 36 & $0 \%$ & $3 \%$ & 17 & $0 \%$ & $0 \%$ \\
\hline & & Positive & & $74 \%$ & $48 \%$ & & $86 \%$ & $67 \%$ & & $100 \%$ & $94 \%$ \\
\hline & \multirow{2}{*}{$\mathrm{DR}$} & Negative & 28 & $7 \%$ & $11 \%$ & 21 & $5 \%$ & $0 \%$ & 12 & $0 \%$ & $0 \%$ \\
\hline & & Positive & & $75 \%$ & $54 \%$ & & $86 \%$ & $76 \%$ & & $100 \%$ & $92 \%$ \\
\hline & \multirow{2}{*}{ GBY } & Negative & 60 & $7 \%$ & $13 \%$ & 58 & $2 \%$ & $3 \%$ & 37 & $0 \%$ & $0 \%$ \\
\hline & & Positive & & $62 \%$ & $57 \%$ & & $76 \%$ & $59 \%$ & & $92 \%$ & $81 \%$ \\
\hline & \multirow{2}{*}{$\begin{array}{ll}\text { LR } \\
\text { L }\end{array}$} & Negative & 48 & $2 \%$ & $13 \%$ & 35 & $0 \%$ & $3 \%$ & 19 & $0 \%$ & $0 \%$ \\
\hline & & Positive & & $79 \%$ & $46 \%$ & & $83 \%$ & $60 \%$ & & $95 \%$ & $89 \%$ \\
\hline & \multirow{2}{*}{ MMR } & Negative & 64 & $5 \%$ & $8 \%$ & 47 & $0 \%$ & $2 \%$ & 27 & $0 \%$ & $0 \%$ \\
\hline & & Positive & & $67 \%$ & $45 \%$ & & $81 \%$ & $64 \%$ & & $93 \%$ & $93 \%$ \\
\hline & \multirow{2}{*}{$\begin{array}{l}\text { TBR } \\
\end{array}$} & Negative & 45 & $4 \%$ & $7 \%$ & 39 & $0 \%$ & $0 \%$ & 19 & $0 \%$ & $0 \%$ \\
\hline & & Positive & & $73 \%$ & $56 \%$ & & $79 \%$ & $67 \%$ & & $95 \%$ & $89 \%$ \\
\hline
\end{tabular}


The analysis of the distributional characteristics of correlation coefficients reveals that:

- A large proportion of the calculated correlations are positive and significant, indicating a dominance of cost side channels of the monetary transmission mechanism. In the overall results, the proportion of positive coefficients is 9 times that of negative coefficients.

- The proportion of insignificant coefficients is very large compared to negative coefficients and in the overall results, the insignificant coefficients are more than 4 times that of negative coefficients.

This analysis reveals that the largest proportion of data from the entire globe supports dominance of cost side channels, and cancellation of the effects of cost and demand side channels. The evidence of dominance of demand side channels is very small.

\section{Conclusion}

A change in interest rate can affect the inflation in three ways:

1. If the demand side effects are dominant, then the inflation shall reduce by increasing interest rate and the relationship between two variables should be negative. In this case, the use of tight of monetary policy shall be effective.

2. If the supply side (cost side) effects are dominant, then inflation shall increase by increasing interest rate and the relationship between two variables should be positive. The use of tight monetary policy in this case shall be counterproductive.

3. If the demand and supply side effects have similar strength, then the effects of interest rate on inflation shall be insignificant and only aggregate production will reduce by increasing the interest rate. Use of tight monetary policy in this case would have no effect on price, but will reduce the aggregate growth.

Obviously, the use of interest rate based monetary policy could be justified only in the first case. Using all definitions of interest rate and inflation, different sample sizes and sample periods we find that the results supporting effectiveness of monetary policy are the weakest. The proportion of negative and significant results is very small. 
The results summarized in the paper indicate that the evidence against the effectiveness of monetary policy are robust to the (a) sample size, (2) sample period, (3) definition of interest rate, (4) definition of inflation, and (5) time lag between interest and inflation. Correlation without structural models provide only a clue not the proof, yet same clues collected from the entire globe formulate a very serious caution.

Thus this analysis concludes that the history monetary policy over the globe does not provide the evidence of functioning of interest rate as a tool of monetary policy as anticipated by the authorities of central banks. The use of interest rate based monetary policy to control inflation is either ineffective or counterproductive and has a bad side effect of reducing the aggregate output. This is a very strong caution for the authorities of central banks and extreme care is needed in the conduct of monetary policy. 


\section{References}

1. Ali, S. Z. (2012). Supply Side Shocks Near Rational Expectations, Cost Channel, and Monetary Policy. DPRC Working Paper (LUMS).

2. Barth, M. J., \& Ramey, V. A. (2001). The Cost Channel of Monetary Transmission. NBER Macroeconomics Annual 2001

3. Bernanke, B. S., \& Gertler, M. (1995). Inside the Black Box: The Credit Channel of Monetary Policy. Journal of Economic Perspective , 9 (4).

4. Chowdhury, I., Hoffmann, M., \& Schabert, A. (2006). Inflation dynamics and the cost channel of monetary transmission. European Economic Review 50 .

5. Ghaffari et al. (2014), Interest Rate and Inflation: A case study of Pakistan, Pakistan Business Review, 16 (3)

6. Ghaffari A (2013), Interest Rate, Inflation and Output; Relationship Revisited, Unpublished MS Economics thesis, IIIE International Islamic University, Islamabad

7. Gibson, A. (1923). The future course of high class investment values, Banker's Magazine, January, pp.

8. Henzel, S., Huslewig, O., Mayer, E., \& Wollmershauser, T. (2007, July). The Price Puzzle Revisited: Can the Cost Channel Explain A Rise In Inflation After A Monetary Policy Shock?

9. Kitchin, J. (1923) Cycles and trends in economic factors, Review of Economics and Statistics, 5, pp.

10. Peake, E.G. (1928) Connection between the prices of commodities and the prices of securities, Bankers' Magazine, 125

11. Qiang, T. J., \& Xin, 1. Z. (2010). Existence of The Cost Channel of China's Monetary Transmission. IEEE 2nd International Conference, School of Economic \& Managment Beihang University Beijing China.

12. Rabanal, P. (2007). Does inflation increase after a monetary policy tightening? Answers based on an estimated DSGE model. Journal of Economic Dynamics \& Control 31.

13. Ravenna, F., \& Walsh, C. E. (2006). Optimal monetary policy with the cost channel. Journal of Monetary Economics 53 , 199-216.

14. Rehman, A. (2014), Relationship Between Energy Prices, Monetary Policy and Inflation; A Case Study of South Asian Economies, Journal of Central Banking Theory and Practice, volume 3 issue 1

15. Rehman, M. (2010). Resolving Controversies About Determinants of Inflation. Unpublished Thesis for PhD Econometrics at IIIE International Islamic University, Islamabad . 
16. Seelig, S. A. (1974). Rising Interest Rates and Cost Push Inflation. The Journal of Finance, vol. 29 (4).

17. Tillmann, P. (2008). Do interest rates drive inflation dynamics? An analysis of the cost channel of monetary transmission. Journal of Economic Dynamics \& Control 32.

18. United States. Congress. Joint Economic Committee. (1977). Price and profits of leading retail food chains, 1970-74: hearings before the Joint Economic Committee, Congress of the United States, Ninety-fifth Congress, first session, March 30 and April 5, 1977. Washington: U.S. Govt. Print. Off.

19. Tooke, T (1838), A History of Prices, and the State of the Circulation, from 1793 to 1837. London: Printed for Longman, Orme, Brown, Green, and Longmanís. 